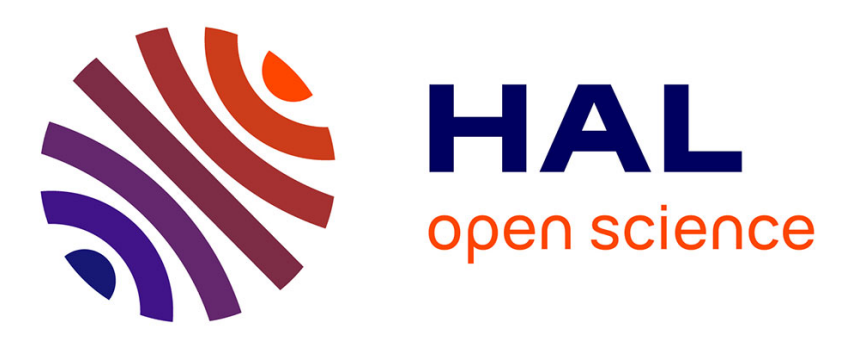

\title{
Ru-Catalyzed Carbonylative Murai Reaction: Directed C3- Acylation of Biomass-Derived 2-Formyl Heteroaromatics
}

Roberto Sala, Fares Roudesly, Luis F Veiros, Gianluigi Broggini, Julie Oble, Giovanni Poli

\section{To cite this version:}

Roberto Sala, Fares Roudesly, Luis F Veiros, Gianluigi Broggini, Julie Oble, et al.. Ru-Catalyzed Carbonylative Murai Reaction: Directed C3- Acylation of Biomass-Derived 2-Formyl Heteroaromatics. Advanced Synthesis and Catalysis, 2020, 362 (12), pp.2486-2493. 10.1002/adsc.202000249 . hal02877185

\section{HAL Id: hal-02877185 \\ https://hal.sorbonne-universite.fr/hal-02877185}

Submitted on 22 Jun 2020

HAL is a multi-disciplinary open access archive for the deposit and dissemination of scientific research documents, whether they are published or not. The documents may come from teaching and research institutions in France or abroad, or from public or private research centers.
L'archive ouverte pluridisciplinaire HAL, est destinée au dépôt et à la diffusion de documents scientifiques de niveau recherche, publiés ou non, émanant des établissements d'enseignement et de recherche français ou étrangers, des laboratoires publics ou privés. 


\title{
Ru-Catalyzed Carbonylative Murai Reaction: Directed C3- Acylation of Biomass-Derived 2-Formyl Heteroaromatics
}

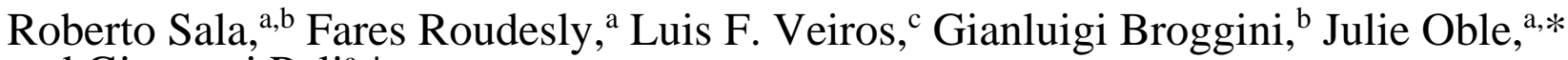 \\ and Giovanni Poli ${ }^{\mathrm{a}, *}$
}

a Sorbonne Université, Faculté des Sciences et Ingénierie, CNRS, Institut Parisien de Chimie Moléculaire, IPCM, 4 place Jussieu, 75005 Paris, France

E-mail: julie.oble@ sorbonne-universite.fr, giovanni.poli@ sorbonne-universite.fr

b Dipartimento di Scienza e Alta Tecnologia (DISAT), Università degli Studi dell'Insubria, Via Valleggio 9, Como (CO), Italy

c Centro de Química Estrutural and Departamento de Engenharia Química, Instituto Superior Técnico, Universidade de Lisboa, Av Rovisco Pais, 1049-001 Lisboa, Portugal

Received:

Dedicated to the memory of Professor Kilian Muñiz

Supporting information for this article is available on the WWW under http://dx.doi.org/10.1002/adsc.201\#\#\#\#\#.

\begin{abstract}
The Murai reaction is a ruthenium-catalyzed transformation leading to alkylated arenes through the $\mathrm{C}-\mathrm{C}$ bond formation between an alkene and an arene bearing a directing group. Discovered in the nineties, this useful $\mathrm{C}-\mathrm{H}$ activation based coupling has been the object of intense study since its discovery. After having studied the Murai reaction on 2-formylfurans of biomass derivation, we describe here the carbonylative version applied to 2formylfurans, 2-formylpyrrols and 2-formylthiophenes. This acylation reaction takes place regioselectively at $\mathrm{C} 3$ position of the heterocyclopentadienes thanks to the installation of removable imine directing groups.
\end{abstract}

\begin{abstract}
The transformation can be achieved by treating the two reaction partners with a catalytic amount of $\mathrm{Ru}_{3}(\mathrm{CO})_{12}$, in toluene at $120-150{ }^{\circ} \mathrm{C}$, after $\mathrm{CO}$ bubbling, at atmospheric pressure. DFT computations of the full catalytic cycle help in deciphering the mechanism of this transformation, and to rationalize the different behaviors depending on the nature of imine directing groups.
\end{abstract}

Keywords: carbonylation; C-H activation; homogeneous catalysis; Murai reaction; ruthenium;

\section{Introduction}

Furfural 1 and the related compound 5(hydroxymethyl)furfural (HMF) 2 are important building blocks ${ }^{[1,2]}$ derived from cyclodehydration of lignocellulosic biomass. ${ }^{[3,4]}$ Since their large-scale production from agricultural residues is developed worldwide, these synthons constitute highly soughtafter raw materials for the sustainable production of value-added compounds for industrial purposes. ${ }^{[5]}$ Consequently, their valorization has become a privileged approach for the replacement of depleting fossil resources. Accordingly, simple transformations of $1^{[6-9]}$ and $2^{[10-13]}$ into more elaborated intermediates, biofuels, as well as some applications in the fields of polymers, ${ }^{[14]}$ have been already reported. Currently, the development of new selective functionalizations of furfurals is becoming a competitive area of research to access more complex furan-containing heterocycles. In this perspective, the selective formation of new bonds through direct transition metal (TM) catalyzed $\mathrm{C}-\mathrm{H}$ activation process, ${ }^{[15-17]}$ without prior modification of the redox state of the aldehyde function, is an extremely attractive eco-compatible strategy that remains scarcely explored on furfurals. In particular, most of the reported examples address arylation, ${ }^{[18-21]}$ alkenylation, ${ }^{[22]}$ alkylation and the alkynylation $^{[23]}$ at $\mathrm{C} 5$ of the furan ring, which is the most electron-rich site. In contrast, C3-H functionalization at the formyl-furan unit via directing groups that overwhelm the natural C5 preference has been scarcely studied ${ }^{[24-26]}$ and remains a challenge.

Within a broad project directed toward the sustainable functionalizations of furfural derivatives focused on TM-catalyzed $\mathrm{C}-\mathrm{H}$ activation process, ${ }^{[27-}$ ${ }^{29]}$ we have recently established that the TM-catalyzed C3-H activation of furfurals can be successfully achieved by using nucleophilic TM catalysts that undergo an initial oxidative addition step of the targeted $\mathrm{C}-\mathrm{H}$ bond. ${ }^{[16]}$ On the contrary, electrophilic TM-complexes that elicit an electrophilic concerted metalation-deprotonation mechanism appear to be proscribed. Accordingly, we reported a $\mathrm{Ru}(0)$ catalyzed hydrofurylation of olefins (Murai reaction $)^{[30,31]}$ that involved the directed $\mathrm{C} 3-\mathrm{H}$ activation of the furan ring through the transient involvement of an amino-imine directing group 
(Figure 1a). ${ }^{[27]} \mathrm{A}$ thorough experimentation supported by DFT calculations revealed that only a bidentate $N, N$ '-imino-amino directing group was able to efficiently promote the desired alkene hydroarylation. This result led us to envisage an extension of this C3functionalization strategy toward a carbonylative version of the Murai reaction ${ }^{[32]}$ using carbon monoxide $(\mathrm{CO})$ as a natural ${ }^{[33]}$ and cheap $\mathrm{C} 1$ source (Figure 1c). To the best of our knowledge, there is only one example reporting the $\mathrm{C} 3$-propionylation of furfural $t$-butylimine, which takes place under high pressure of $\mathrm{CO}$ and ethylene (Figure 1b) ${ }^{[34,35]}$ From a synthetic viewpoint, the direct C3-acylation of furfurals is a particularly attractive transformation, as it is complementary to the Friedel-Crafts acylation, which generally occurs at the $\mathrm{C} 4$ position of the 2formylfuran unit. ${ }^{[36]}$

Previous works: C3-alkylation (eq. a ); C3-propionylation (eq. b) of furfurylimines

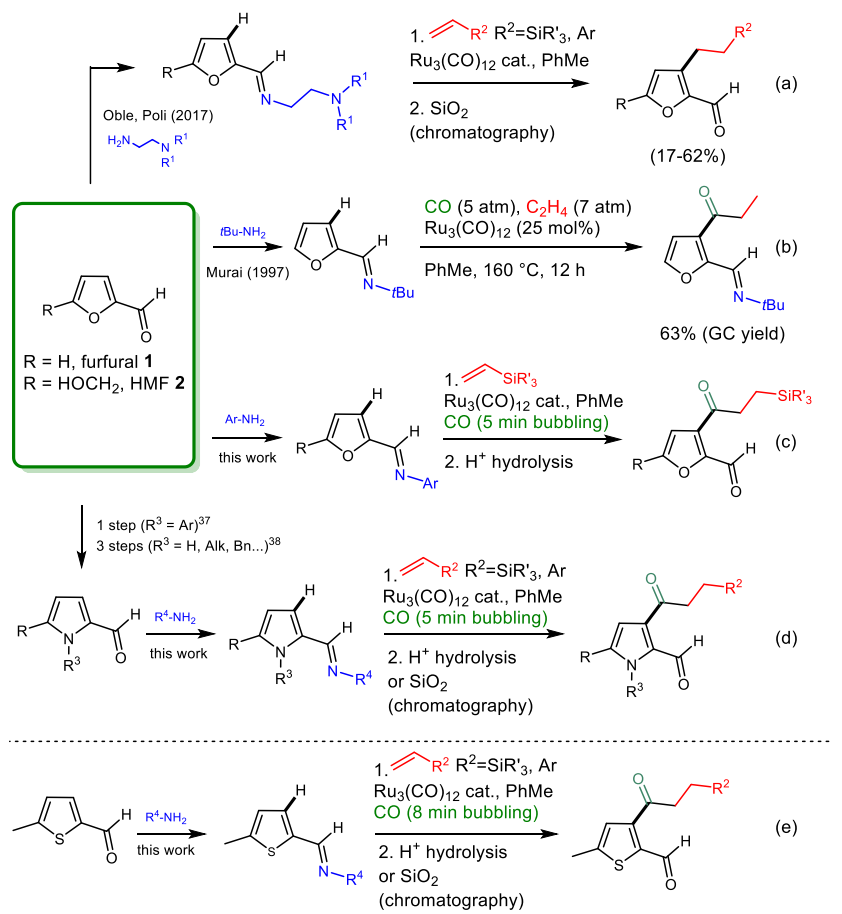

This work: C3-acylation of furfurylimines (eq. c); of 2-formylpyrrole-imines (eq. d); of 2-formylthiophene-imines (eq. e)

Figure 1. Ru-catalyzed direct $\mathrm{C} 3$-functionalization of furfural, 2-formylpyrrole and 2-formylthiophene derivatives.

Pyrrole 2-carboxaldehyde was another substrate considered for our carbonylative study (Figure 1d). Given its accessibility from furfural in one step, through a Paal-Knorr synthesis, ${ }^{[37]}$ or in three steps through a carbonyl reduction / Achmatowicz rearrangement / Maillard condensation sequence, ${ }^{[38]}$ this substrate can be regarded as a biomass-derived building block, too. Extension to thiophene 2carboxaldehyde was also envisaged, to verify the generality of the heterocyclopentadiene family (Figure 1e). Although some TM-catalyzed direct functionalizations of pyrrole or thiophene 2- carboxaldehydes have been reported, these studies have mainly addressed C5-arylation ${ }^{[39-42]}$ and C5alkylation, ${ }^{[23]}$ while the $\mathrm{C} 3$-functionalization has been only very marginally explored. ${ }^{[24,43]}$

Herein, we disclose the first C3-carbonylative versions of the Murai reaction on furfural derivatives, pyrrole 2-carboxaldehydes and their benzo-fused analogs - indoles - as well as on thiophene 2carboxaldehydes, through their corresponding aldimines, which act as removable directing groups. Optimal imines to be used for each type of substrate were established through an in-depth experimental screening, while DFT computations provided mechanistic insights. ${ }^{[4]}$

\section{Results and Discussion}

Development of a Ru-catalyzed C3-acylation of furfurylimines. From the outset of this study, the use of an atmospheric pressure of $\mathrm{CO}$ has been chosen as opposed to the use of high pressure, which requires a special equipment. Accordingly, the reaction media were saturated by bubbling $\mathrm{CO}$ during $5 \mathrm{~min}$ before turning off the cylinder and heating the reaction mixture. We started our investigation by testing a series of furfurylimines $(\mathbf{F 3}(\mathbf{a}-\mathbf{j}))^{[45]}$ - readily prepared in one step from furfural $\mathbf{1}$ - in the presence of triethoxyvinylsilane (4 equiv.) as the alkene partner and $\mathrm{Ru}_{3}(\mathrm{CO})_{12}(5 \mathrm{~mol} \%)$ as the pre-catalyst, in toluene at $120-135{ }^{\circ} \mathrm{C}$ (see Supporting Information, Tables 1 and 2). After some preliminary experiments, optimal results could be obtained using the aromatic electronrich $p$-methoxyphenylimine (PMP-imine) F3c, which led to the desired C3-acylated imine F4ca in 66\% yield (85\% NMR yield) at $120^{\circ} \mathrm{C}$ (Scheme 1). Noteworthy, in the absence of $\mathrm{CO}$ atmosphere, this PMP-imine displayed a very low "classic Murai" reactivity. ${ }^{[27]}$ Furthermore, $t$-butylimine F3a as well as the $N, N$ 'bidentate imine F3b, which previously gave satisfactory results in the C3-propionylation under pressure of $\mathrm{CO}$ and ethylene (Figure $1 \mathrm{~b})^{[34]}$ as well as in the C3-alkylation (classic Murai) (Figure 1a), ${ }^{[27]}$ respectively, failed to afford the corresponding alkylated or acylated products (Scheme 1).

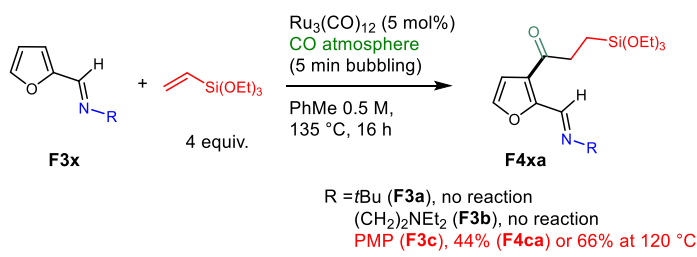

Scheme 1. Ru-catalyzed direct C3-acylation of furfurylimines: screening of the imine directing groups. ${ }^{[45]}$

The scope of this C3-carbonylative Murai reaction was subsequently studied with the PMP-imine F3c in the presence of a variety of trialkoxy-, trialkyl- and triarylvinylsilanes (4 equiv.) and $\mathrm{Ru}_{3}(\mathrm{CO})_{12}(5 \mathrm{~mol} \%)$, in toluene $(0.5 \mathrm{M})$ at $120-135^{\circ} \mathrm{C}$ during $16-24 \mathrm{~h}$. 

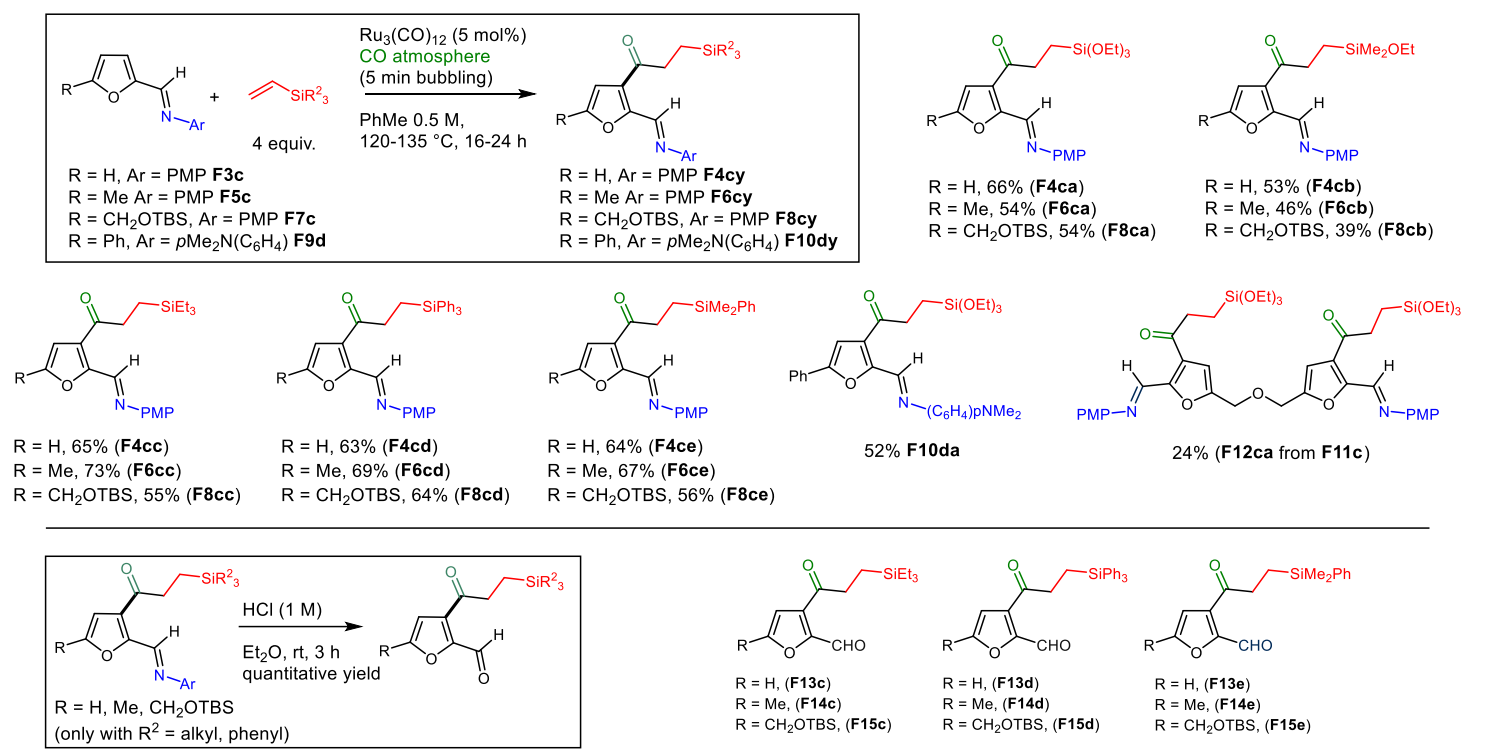

Scheme 2. Scope of Ru-catalyzed direct C3-acylation of PMP-furfurylimines (top) and acid hydrolysis of the C3-acylatedimines leading to $\mathrm{C} 3$-acylated furfurals (PMP = p-methoxyphenyl, TBS = tert-butyldimethylsilyl) (bottom).

A rapid chromatographic purification on deactivated silica gel allowed to obtain moderate to good yields of the corresponding C3-acylated imines F4c(a-e) (53$66 \%$ isolated yields) (Scheme 2, top). However, in the case of trialkyl- and triaryl-vinylsilanes, good yields were only obtained when the mixtures were heated at $135^{\circ} \mathrm{C}$. The reaction was also studied with styrenes, which unfortunately failed to react. The scope was next extended to C5-substituted furfurals such as 5methylfurfural-PMP-imine F5c and the TBS-Oprotected HMF PMP-imine F7c. In the event, the corresponding C3-acyclated imines F6c(a-d) and F8c(a-d) could be isolated in reasonable to good yields. The 5-phenyl derivative was also effective, but only through its $p$-dimethylaminophenyl-imine F9d, whereas the PMP-imine led to complex results. Besides, a double coupling was successfully achieved with the HMF-dimer diimine F11c using eight equivalents of triethoxyvinylsilane, which gave the diacylated HMF imine dimer F11ca. Finally, the subsequent acid hydrolysis of the alkyl and aryl silyl derivatives F(4-8)cy enabled access to the C3acylated-furfurals $\mathbf{F}(\mathbf{1 3 - 1 5}) \mathbf{y}$ in quantitative yields (Scheme 2, bottom).

Ru-catalyzed C3-acylation of pyrrole and indole 2carboxaldimines. We continued our investigations on pyrrole 2-carboxaldimines, easily prepared from pyrrole 2-carboxaldehyde P1. The classic Murai reaction conditions ${ }^{[27]}$ were first tested on various $N$ benzylpyrrole imines $\mathbf{P} 3_{\mathrm{Bn}}(\mathbf{a}-\mathbf{c})$ in the presence of triethoxyvinylsilane (3 equiv.) and $\mathrm{Ru}_{3}(\mathrm{CO})_{12}$ (5 $\mathrm{mol} \%)$, in toluene $(0.5 \mathrm{M})$ at $135{ }^{\circ} \mathrm{C}$ during $16 \mathrm{~h}$. In the event, $N, N^{\prime}$-bidentate imines $\mathbf{P} \mathbf{3}_{\mathbf{B n}}(\mathbf{a}-\mathbf{b})$ and $p$ methoxyphenylimine $\mathbf{P} \mathbf{3}_{\mathrm{Bn}} \mathbf{c}$ led to traces of the corresponding $\mathrm{C} 3$-alkylated products $\mathbf{P 4}{ }^{\prime}{ }_{\mathrm{Bn}}(\mathbf{a}-\mathbf{c}) \mathbf{a}$ together with the $\mathrm{C} 3$-acylated ones $\mathbf{P 4} \mathbf{B}_{\mathbf{B n}}(\mathbf{a}-\mathbf{c}) \mathbf{a}$ (Scheme 3, top). Further optimization tests did not allow to selectively obtain the $\mathrm{C} 3$-alkylated products
(Supporting Information, Table 3). We investigated next the carbonylative version by prior $\mathrm{CO}$ bubbling during $5 \mathrm{~min}$, as from our previous protocol with the oxygen-based substrates. To our delight, the two pyrrole substrates $\mathbf{P} \mathbf{3}_{\mathbf{B n}}(\mathbf{a}-\mathbf{b})$, bearing a bidendate aminoimine group, as well as of the two substrates $\mathbf{P} 3_{\mathrm{Bn}}(\mathbf{c}-\mathbf{d})$ bearing an electron-rich aromatic imino group, in the presence of triethoxyvinylsilane (4 equiv.), allowed us to isolate exclusively the acylated products $\mathbf{P} 4_{\mathrm{Bn}}(\mathbf{a}-\mathbf{d}) \mathbf{a}$ in excellent NMR yields (Scheme 3 , bottom). The results, accompanied by additional optimization parameters such as the nature of the $\mathrm{N}$ protecting group of the pyrrole ring and the number of silane equivalents are summarized in the Supporting Information, Tables 4 and 5.

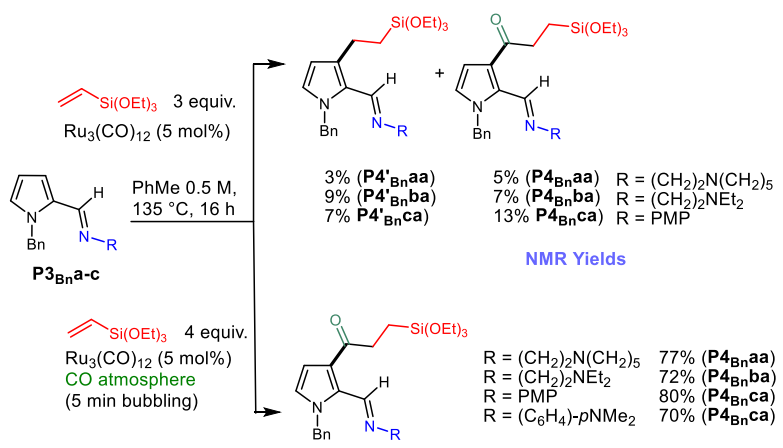

Scheme 3. Ru-catalyzed Murai reaction and carbonylative variant of pyrrole 2-carboxaldimines.

The scope of the C3-carbonylative Murai reaction on pyrrole derivatives was carried out on the $N, N^{\prime}$ bidentate imine $\mathbf{P 3}_{\mathbf{B n}} \mathbf{a}$, in the presence of $\mathrm{Ru}_{3}(\mathrm{CO})_{12}(5$ $\mathrm{mol} \%$ ), and triethoxy-, triaryl-, trialkyl-vinylsilanes or styrene derivatives (4 equiv.), in toluene $(0.5 \mathrm{M})$ at $135{ }^{\circ} \mathrm{C}$ under $\mathrm{CO}$ atmosphere during $16 \mathrm{~h}$ (Scheme 4, top). 

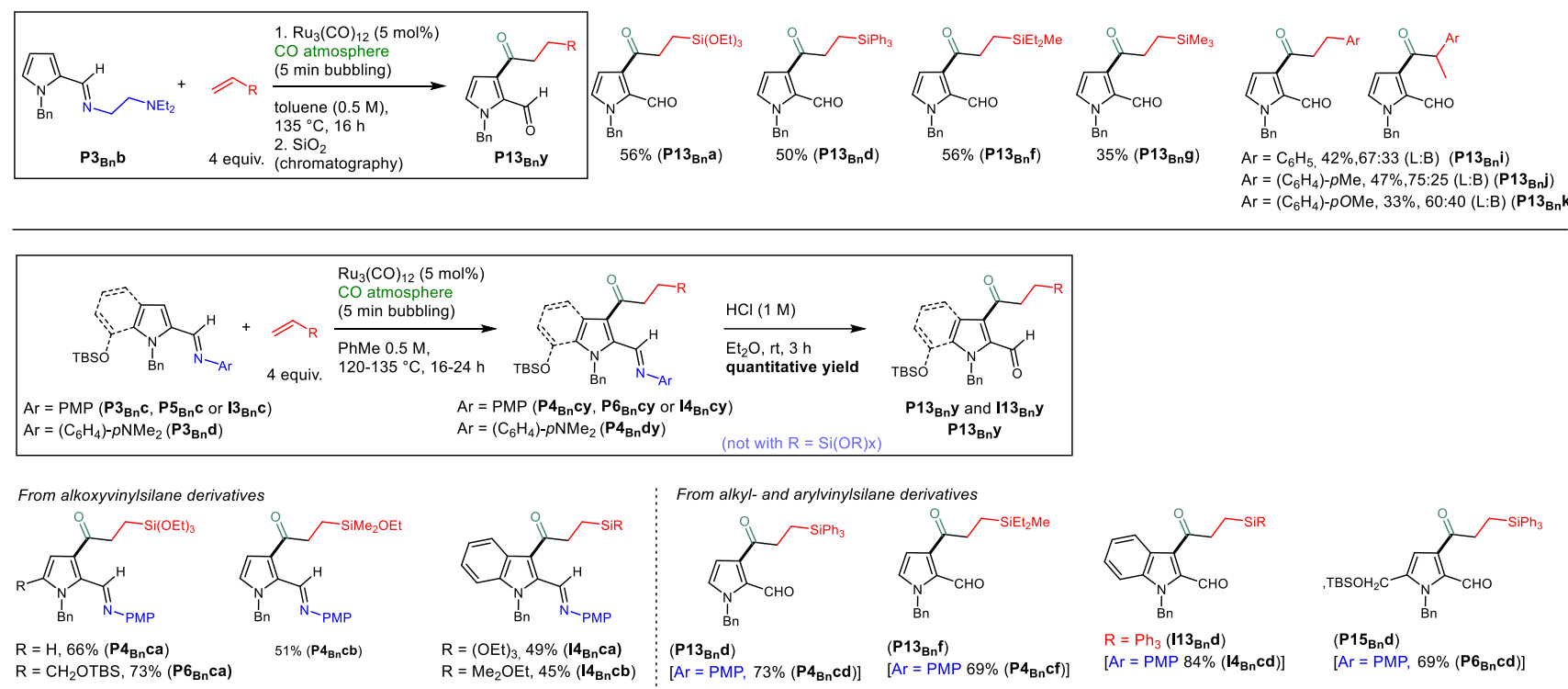

$\mathrm{R}=\mathrm{Et}_{2} \mathrm{Me}\left(\mathbf{1 1 3 _ { \mathrm { Bn } } \mathrm { f } )}\right.$

$\left[\mathrm{Ar}=\mathrm{PMP} 70 \%\left(14_{\mathrm{Bn}} \mathrm{cf}\right)\right]$

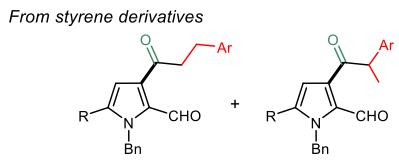

$\mathrm{Ar}=\mathrm{C}_{6} \mathrm{H}_{5}\left(\mathbf{P} 13_{\mathrm{Bn}} \mathrm{i}\right)\left[\mathrm{Ar}=\left(\mathrm{C}_{6} \mathrm{H}_{4}\right)-p \mathrm{NMe}_{2} 75 \%\left(\mathbf{P 4}_{\mathbf{B n}} \mathbf{d i}\right) 72: 28(\mathrm{L:B})\right]$

$\mathrm{Ar}=\left(\mathrm{C}_{6} \mathrm{H}_{4}\right)-p \mathrm{Me}\left(\mathbf{P 1 3} \mathbf{B r i}_{\mathrm{Bj}}\right)\left[\mathrm{Ar}=\left(\mathrm{C}_{6} \mathrm{H}_{4}\right)-p \mathrm{NMe}_{2} 71 \%\left(\mathbf{P 4}_{\mathrm{B}} \mathbf{d j}\right) 69: 31\right.$ (L:B)

$\mathrm{Ar}=\left(\mathrm{C}_{6} \mathrm{H}_{4}\right)-p \mathrm{OMe}\left(\mathbf{P} \mathbf{1 3}_{\mathbf{B n}} \mathbf{k}\right)\left[\mathrm{Ar}=\left(\mathrm{C}_{6} \mathrm{H}_{4}\right)-p \mathrm{NMe}_{2} 66 \%\left(\mathbf{P 4} \mathbf{B}_{\mathbf{B} \mathbf{n}} \mathbf{d k}\right) 51: 49(\mathrm{~L}: \mathrm{B})\right]$

$\mathrm{R}=\mathrm{CH}_{2} \mathrm{OTBS}$

$\mathrm{Ar}=\left(\mathrm{C}_{6} \mathrm{H}_{4}\right)-\mathrm{pOMe}\left(\mathbf{P 1 5} 5_{\mathbf{B n}} \mathbf{k}\right)\left[\mathrm{Ar}=\mathrm{PMP} 56 \%\left(\mathbf{P} \mathbf{6}_{\mathbf{B n}} \mathbf{c k}\right) 64: 36(\mathrm{~L}: \mathrm{B})\right]$

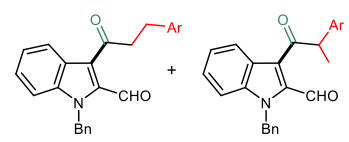

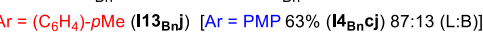

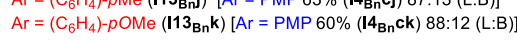

Scheme 4. Ru-catalyzed directed C3-acylation of pyrrole and indole 2-carboxaldimines.

The use of the alkylimine allowed the direct isolation of the alkylated aldehydes $\mathbf{P} 13_{\mathbf{B n}} \mathbf{y}$ through silica gel purification. The reaction was additionally explored on PMP-imines, which are robust aromatic imines allowing the use of a larger variety of trialkoxyvinylsilanes. In the event, these derivatives gave us access to different $\mathrm{C} 3$-acylated imines from pyrrole $\mathbf{P} \mathbf{3}_{\mathrm{Bn}} \mathbf{c}$, the C5-substituted pyrrole $\mathbf{P} 5_{\mathrm{Bn}} \mathbf{c}^{[38]}$ and indole $\mathbf{I} \mathbf{3}_{\mathrm{Bn}} \mathbf{c}$ (Scheme 4, bottom). With trialkyl- and triaryl-vinylsilanes, acid hydrolysis of the $\mathrm{C} 3$-acylated imines $\mathbf{P} \mathbf{4}_{\mathbf{B n}} \mathbf{c}(\mathbf{d}, \mathbf{f}), \mathbf{P 6}_{\mathbf{B n}} \mathbf{c d}$ and $\mathbf{I} \mathbf{4}_{\mathbf{B n} \mathbf{n}} \mathbf{c}(\mathbf{d}, \mathbf{f})$ led to the corresponding aldehydes $\mathbf{P 1 3} \mathbf{B n}_{\mathbf{B n}}(\mathbf{d}, \mathbf{f}), \quad \mathbf{P 1 5} \mathbf{B n}_{\mathbf{B n}} \mathbf{d}$ and $\mathbf{I 1 3} 3_{\mathbf{B n}}(\mathbf{d}, \mathbf{f})$ in good yields over two steps. In the case of styrene derivatives, best yields were obtained using dimethylaminophenyl-imine $\mathbf{P} \mathbf{3}_{\mathbf{B n}} \mathbf{d}$ for pyrrole, whereas PMP-imines $\mathbf{P} \mathbf{5}_{\mathbf{B n}} \mathbf{c}$ and $\mathbf{I} \mathbf{3}_{\mathbf{B n}} \mathbf{c}$ led to desired product with satisfactory results.

In summary, the reactivity of pyrrole 2carboxaldimines and of the benzo-fused analogues does not parallel that observed with the corresponding furfurylimines. Indeed, while in the case of the $O$ based heterocyclic substrates, bidentate imines allow $\mathrm{C} 3$-alkylation and electron-rich aromatic imines allow C3-acylation, with the $N$-based heterocyclopentadienes both imine types - bidendated as well as monodentated - allow the C3-acylation and forbid the "classical Murai".

Ru-catalyzed C3-alkylation and acylation of thiophene 2-carboxaldimines. To expand the scope of this new method, the Murai reactions were also performed on thiophene 2-carboxaldimines, whether as bidentate or monodentate imines (PMP-imine).
Although the thienyl substrates proved to be less reactive than the corresponding furyl and pyrrolyl derivatives, a reactivity trend analogous to the one of the $O$-based heterocyclopentadienes was manifest. Indeed, the bidentate imine $\mathbf{T 5} \mathbf{b}$ reacted as expected with triethoxyvinylsilane - but not with triethylvinylsilane and styrene - in presence of $\mathrm{Ru}_{3}(\mathrm{CO})_{12}(5 \mathrm{~mol} \%)$, in toluene $(0.5 \mathrm{M})$ at $135{ }^{\circ} \mathrm{C}$, leading to the corresponding $\mathrm{C} 3$-alkylated aldehyde T14a in a moderate yield (Scheme 5, top), and the corresponding acylated products were never detected, even when working in the presence of $\mathrm{CO}$ atmosphere.

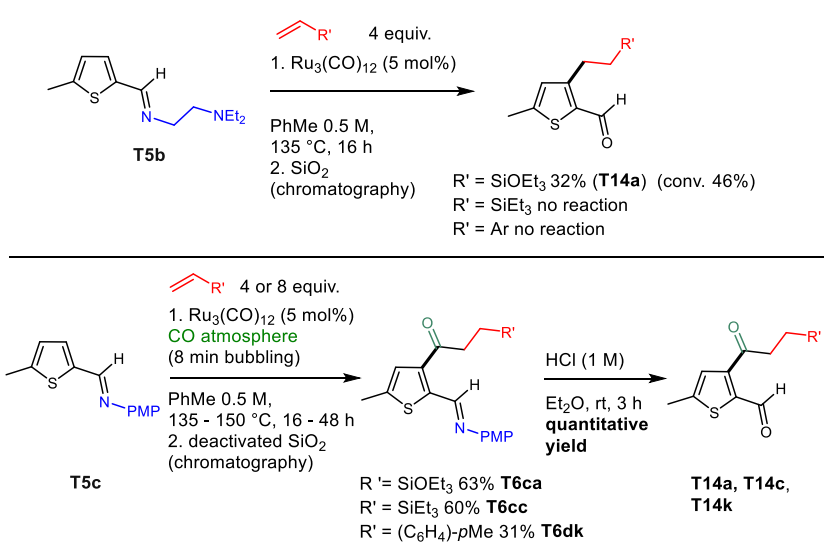

Scheme 5. Ru-catalyzed Murai reaction and carbonylative variant of thiophene 2-carboxaldimines. 
Conversely, treatment of PMP-imine T5c with triethoxy- (T6ca) or triethyl-vinylsilanes (T6cc) at $135^{\circ} \mathrm{C}$ gave traces of the corresponding alkylated and acylated products in the absence of $\mathrm{CO}$, and moderate yields of the corresponding $\mathrm{C} 3$-acylated products under $\mathrm{CO}$ atmosphere (Scheme 5, bottom). Noteworthy, these reactions required an increase of the $\mathrm{CO}$ bubbling time from 5 to 8 min to totally suppress the competing alkylated product. The reaction was also possible with a styrene derivative ( 8 equiv.) by increasing the temperature $\left(150{ }^{\circ} \mathrm{C}\right)$ and the reaction time $(48 \mathrm{~h})$. As previously observed, the subsequent acid hydrolysis of C3-acylated imines T6(c,d)y enabled access to the C3-acylated-aldehydes T14y in quantitative yields.

Synthetic applications. The post-functionalization of some C3-acylated five-membered heterocycles were next evaluated. First, Tamao-Fleming oxidations were performed on the C3-acylated furfurylimines $F(4,6)$ ca as well as on pyrrole $\mathbf{P} \mathbf{4}_{\mathbf{B n}} \mathbf{c a}$ and indole 2carboxaldimines $\mathbf{I} \mathbf{4}_{\mathbf{B n}} \mathbf{c b}$. Thus, treatment of the above compounds with $\mathrm{KF}, \mathrm{KHCO}_{3}$ and $\mathrm{H}_{2} \mathrm{O}_{2}$ led to corresponding alcohols in good yields, without further optimizations (Scheme 6, top). Furthermore, treatment of aldehydes (P,I)13 $\mathbf{B n} \mathbf{f}$ with KHMDS (1.2 equiv.) gave the corresponding aldols $(\mathbf{P}-\mathbf{I}) \mathbf{1 8}_{\mathbf{B n}} \mathbf{f}$ in moderate yields ( $d r$ 1:1), without traces of the dehydrated products (Scheme 6, bottom)

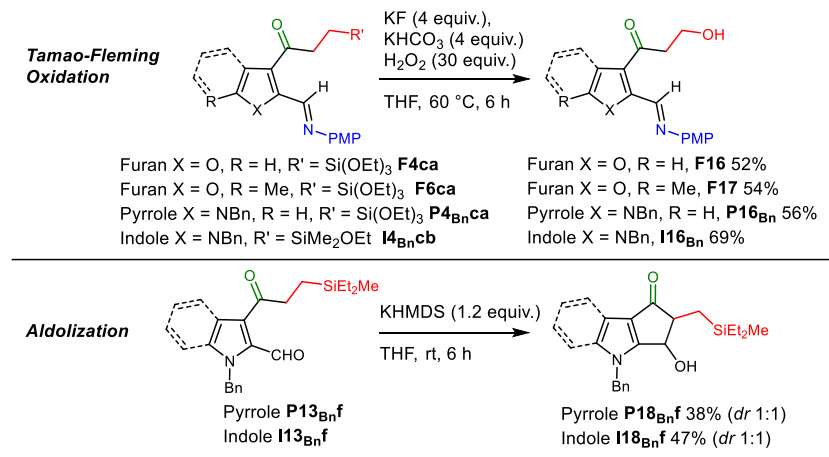

Scheme 6. Synthetic applications.

Mechanistic investigations. The mechanism of C3acylation was studied via DFT calculations ${ }^{[46]}$ for pyrrole $\mathbf{P} \mathbf{3}_{\mathbf{B n}} \mathbf{c}$ with trimethoxyvinylsilane used as alkene model. The generally accepted mechanism for the Murai reaction and its carbonylative variant involves a mononuclear $\operatorname{Ru}(0)$ complex as the first active species. ${ }^{[47,48]}$ We thus anticipated the conversion of the $\mathrm{Ru}_{3}(\mathrm{CO})_{12}$ pre-catalyst into a mononuclear ruthenium carbonyl by $\mathrm{Ru}-\mathrm{Ru}$ breaking and $\mathrm{CO}$ releasing, ${ }^{[49]}$ similarly to what previously assumed in the mechanistic study of the Murai reaction with furan substrates. Nevertheless, it should be noticed that the simplicity of the model employed may limit the scope of the calculations. The simplified calculated catalytic cycle is represented in Scheme 7, while the complete reaction free energy profile is presented as Supporting Information.

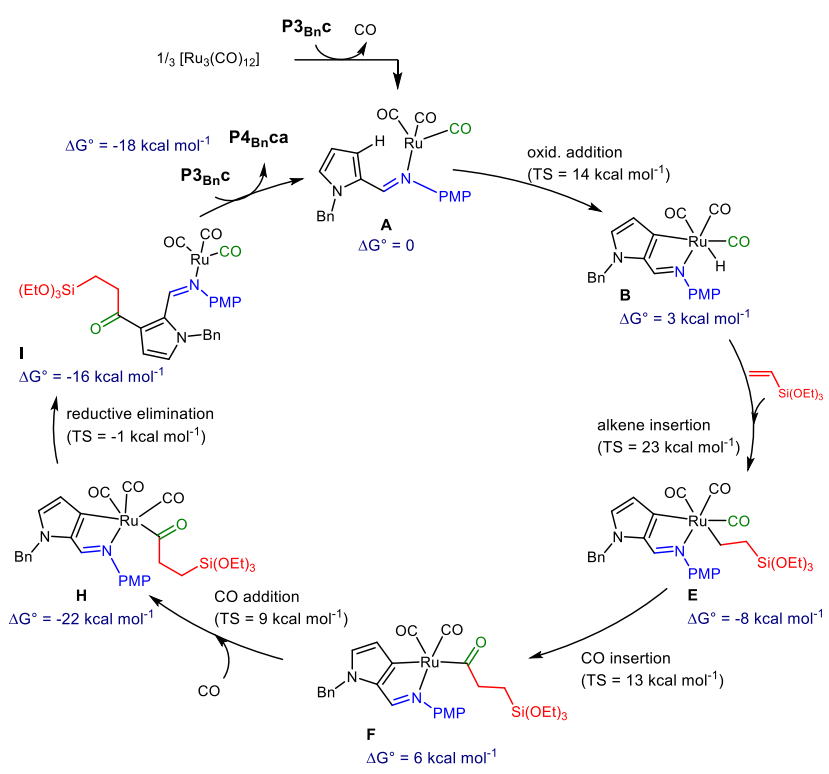

Scheme 7. Simplified catalytic cycle. Free energy values relative to the initial reactant, $\mathrm{A}$.

The initial species in the proposed mechanism has the imine substrate coordinated to the $\mathrm{Ru}(\mathrm{CO})_{3}$ fragment (A in the calculations). From $\mathbf{A}$, there is an oxidative addition of the $\mathrm{C} 3-\mathrm{H}$ bond in the pyrrole ring to the metal center with formation of an hydride intermediate, complex $\mathbf{B}$, in the opening step of the mechanism. Thus, the metal is formally oxidized from $\mathrm{Ru}^{0}$, in $\mathbf{A}$, to $\mathrm{Ru}^{\mathrm{II}}$, in $\mathbf{B}$. That is a fairly easy step with a barrier of $14 \mathrm{kcal} / \mathrm{mol}$ and a free energy balance of $\Delta G=3 \mathrm{kcal} / \mathrm{mol}$. The reaction proceeds with olefin coordination followed by insertion into the $\mathrm{Ru}-\mathrm{H}$ bond. Alkene coordination occurs with simultaneous break of imine coordination (intermediate $\mathbf{C}$, see Supporting Information) and the insertion process results in a high energy intermediate where coordination of the newly formed alkyl ligand is stabilized by a $\mathrm{C}-\mathrm{H}$ agostic interaction (intermediate D). Recoordination by the $\mathrm{N}_{\text {imine }}$ lone pair breaks the agostic interaction and results in the alkyl intermediate E.

That process overcomes a barrier of $23 \mathrm{kcal} / \mathrm{mol}$ associated with the transition state for olefin insertion $\left(\mathbf{T S}_{\mathbf{C D}}\right)$. This is the highest energy transition state along the path and corresponds to the determining transition state of the process (TDTS). Overall, alkene insertion into the hydride complex - from $\mathbf{B}$ to $\mathbf{E}$ - is a favorable process with $\Delta G=-11 \mathrm{kcal} / \mathrm{mol}$. The mechanism proceeds with CO insertion into the alkyl ligand in $\mathbf{E}$, resulting in the acyl complex $\mathbf{F}$. The $\mathrm{CO}$ insertion step is clearly endergonic with $\Delta G=14 \mathrm{kcal} / \mathrm{mol}$ and the corresponding transition state $\left(\mathbf{T S}_{\mathbf{E F}}\right)$ has an energy of $13 \mathrm{kcal} / \mathrm{mol}$ relative to $\mathbf{A}$, corresponding, thus, to a 21 $\mathrm{kcal} / \mathrm{mol}$ barrier, measured from E. In the following step, a new CO molecule coordinates the metal, from $\mathbf{F}$ to $\mathbf{H}$, in a very facile process with a transition state only $3 \mathrm{kcal} / \mathrm{mol}$ less stable than $\mathbf{F}$. The resulting acyl complex, $\mathbf{H}$, is the most stable species along the entire mechanism, being $22 \mathrm{kcal} / \mathrm{mol}$ more stable than the 
initial reactant and corresponds to the determining intermediate in the process (TDI). In the final step, the acyl ligand inserts into the $\mathrm{Ru}-\mathrm{C}_{\text {ring }}$ bond in a reductive elimination process that brings the metal back to its initial oxidation state, $\mathrm{Ru}^{0}$. This last step is endergonic $(\Delta G=6 \mathrm{kcal} / \mathrm{mol})$ and overcomes a barrier of 21 $\mathrm{kcal} / \mathrm{mol}$, measured from the acyl intermediate, $\mathbf{H}$, to the following transition $\mathbf{T S}_{\mathbf{H I}}$ that is $1 \mathrm{kcal} / \mathrm{mol}$ more stable than A. The entire cycle is exergonic, the final species (I) being $16 \mathrm{kcal} / \mathrm{mol}$ more stable than the initial reagent $(\mathbf{A})$ and has an overall barrier of 27 $\mathrm{kcal} / \mathrm{mol}$, measured from $\mathbf{H}$ to the transition state for olefin insertion of the following cycle, $\mathbf{T S}_{\mathbf{C D}}$. Closing of the cycle, with liberation of the acylated product and coordination of a new imine substrate, from I back to A, has a favorable free energy balance of $\Delta G=-2$ $\mathrm{kcal} / \mathrm{mol}$.

Comparison between the reductive elimination and the $\mathrm{CO}$ insertion steps starting from the common tricarbonyl intermediates deriving from furan imine F3b and pyrrole imine $\mathbf{P} \mathbf{3}_{\mathbf{B n}} \mathbf{b}$ after olefin insertion, shows that the barrier associated with the reductive elimination is higher than the one associated with the $\mathrm{CO}$ insertion, by $34 \mathrm{kcal} / \mathrm{mol}$ in the case of the furan imine and by $6 \mathrm{kcal} / \mathrm{mol}$ in the case of the pyrrole imine (Figure 2). This confirms that in the presence of $\mathrm{CO}$ atmosphere the reductive elimination step is always intrinsically disfavored with respect to $\mathrm{CO}$ insertion. This result is in line with the fact that furan imines of type $\mathbf{F c}$ and $\mathbf{F d}$ as well as pyrrole imines of type $\mathbf{P}_{\mathbf{B n}} \mathbf{b}$ and $\mathbf{P}_{\mathbf{B n}} \mathbf{c}$ showed successful acylative reactivity under the reaction conditions, but is not in accord with the behavior of the furan derivative of type $\mathbf{F b}$, which carries the aliphatic imine with amine tail. We speculate that the failure to observe acylative reactivity in this latter case has to be due to an energetically prohibitive step upstream in the cycle, probably at the alkene insertion stage. Conversely, successful alkylative reductive elimination - i.e. classic Murai reactivity - obtained carrying out the reaction in the absence of $\mathrm{CO}$ bubbling, could be obtained only in the case of the furan derivatives such as F3b, bearing an imine derived from an aliphatic amine in turn carrying a pending aliphatic amine tail, while it failed with the furan derivatives carrying the aromatic PMP imine as well as with all the pyrrole derivatives tested. These conclusions are also in line with the results obtained with 2-formyl-thiophene derivatives which have shown a similar reactivity trend to furfuryl derivatives depending on the imine used. It thus appears that, at least within the heterocyclopentadiene substrates investigated in our studies, the classic Murai reactivity can be achieved only when the following two features are met at the same time: furan (or thienyl) nucleus, and aliphatic imine with an amine tail. We speculate that a necessary - though not sufficient - condition to achieve the classic Murai reaction is the presence of an alkylamine-derived imine directing group, whose nitrogen atom stays coordinated to the $\mathrm{Ru}$ atom throughout the catalytic cycle, while the carbonylative Murai reaction necessarily involves the decoordination of the imine nitrogen atom to allow alkene insertion.

Competition between $\mathrm{CO}$ insertion into the alkyl chain and into the coordinated pyrrole ring was also addressed by the calculations. The results indicate that the second process is clearly unfavorable, the energy difference between the respective transition states being of $10 \mathrm{kcal} / \mathrm{mol}$ (compare Figure S3 with S5 in SI).

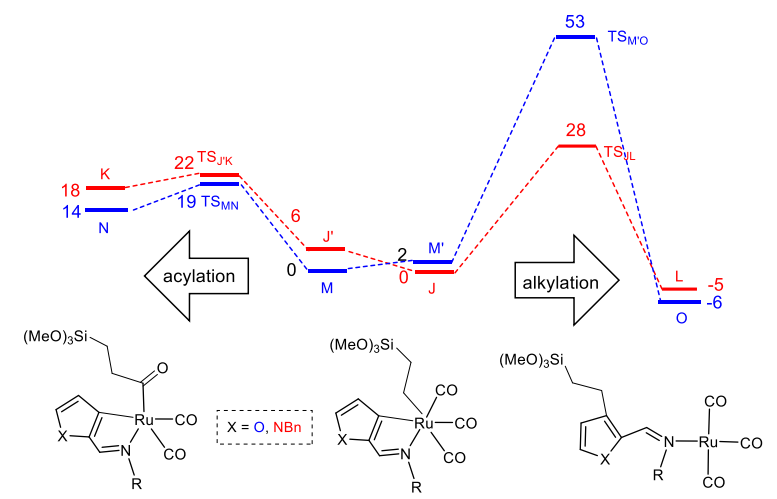

Figure 2. Free energy profile (kcal/mol) for the comparison between $\mathrm{CO}$ insertion into the alkyl ligand (left side) and insertion of the alkyl into the heterocyclic ring (right side), $\mathrm{R}=\left(\mathrm{CH}_{2}\right)_{2} \mathrm{~N}\left(\mathrm{CH}_{2}\right)_{3} .{ }^{[50]}$

\section{Conclusion}

In summary, this work showed that the carbonylative Murai reaction (i.e. the $\mathrm{Ru}(0)$-catalyzed acylation in the presence of an alkene and excess carbon monoxide at atmospheric pressure) can be successfully accomplished at the $\mathrm{C} 3$ position of 2 -formyl heterocyclopentadienes thanks to the easy installation of removable imine directing groups on the formyl function. The carbonylative $\mathrm{C}-\mathrm{H}$ activation couplings developed in this study, greatly expand the scope of the Murai reaction on the heterocyclopentadienes, allowing to almost complete the puzzle comprising the possible alkylative and acylative combinations (Scheme 8).

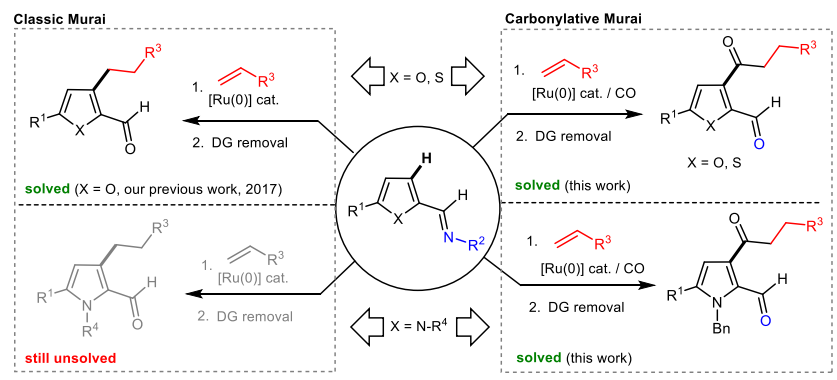

Scheme 8. State of the art of the Murai reaction on 2-formyl heterocyclopentadiene after this work.

These results are of especial value, if we consider that the furan substrates are of direct biomass derivation 
(furfural and hydroxymethylfurfural), and that pyrroles can be in turn obtained from furans. This work, summed with our previous study on the Murai reaction $^{[27]}$ indicate that the outcome of these coupling reactions highly depend on the subtle interplay between the nature of the heteroatom of the heterocycle and on the nature of the directing imine function. DFT computations shed light on the complex mechanistic puzzle associated to these coupling reactions, although a definitive solution has to wait for further work. Future studies will be directed, inter alia, to achieve the fourth and last combination left unsolved: the classical Murai reaction from 2formylpyrrole derivatives.

\section{Experimental Section}

\section{General procedure for the $\mathrm{Ru}$-catalyzed carbonylative Murai reaction.}

To an ace pressure tube, dried under vacuum, was added the $\mathrm{Ru}_{3}(\mathrm{CO})_{12}(16 \mathrm{mg}, 0.025 \mathrm{mmol}, 5 \mathrm{~mol} \%$ ). The aldiminefuran, -pyrrole or -indole ( $0.5 \mathrm{mmol}, 1$ equiv.) dissolved in toluene $(0.5 \mathrm{M})$, was then added followed by the vinyl partner (2-4 mmol, 4-8 equiv.). The solution was bubbled with $\mathrm{CO}$ gas for $5 \mathrm{~min}$, before closing the sealing tube and heating at $120-135{ }^{\circ} \mathrm{C}$ for $16-24 \mathrm{~h}$. The mixture was filtered over celite and washed with $\mathrm{CH}_{2} \mathrm{Cl}_{2}$. The volatiles were removed under reduced pressure and the crude was then purified by column chromatography on (deactivated) silica gel affording the corresponding C3-acylated imine (or C3acylated aldehyde)

\section{Acknowledgements}

The authors would like to acknowledge Horizon 2020 ERANetLAC project CelluloseSynThech for financial support as well as CNRS, Sorbonne Université and Labex Michem (Investissements d'Avenir program under reference ANR-11-IDEX-0004-02). Support through CMST COST Action, CA15106 (CHAOS) is also gratefully acknowledged. L.F.V. acknowledges Fundação para a Ciência e Tecnologia, UID/QUI/ 00100/2013.

\section{References}

[1] J. J. Bozell, G. R. Petersen, Green Chem. 2010, 12, 539-554.

[2] B. Liu, Z. Zhang, ChemSusChem 2016, 9, 2015-2036.

[3] L. T. Mika, E. Cséfalvay, Á. Németh, Chem. Rev. 2018, 118, 505-613.

[4] T. A. Bender, J. A. Dabrowski, M. R. Gagné, Nat. Rev. Chem. 2018, 2, 35-46.

[5] D. E. Resasco, B. Wang, D. Sabatini, Nat. Catal. 2018, $1,731-735$.

[6] R. Mariscal, P. Maireles-Torres, M. Ojeda, I. Sádaba, M. L. Granados, Energy Environ. Sci. 2016, 9, 1144-1189.

[7] X. Li, P. Jia, T. Wang, ACS Catal. 2016, 6, 7621-7640.
[8] K. Yan, G. Wu, T. Lafleur, C. Jarvis, Renew. Sustain. Energy Rev. 2014, 38, 663-676.

[9] A. Bohre, S. Dutta, B. Saha, M. M. Abu-Omar, ACS Sustain. Chem. Eng. 2015, 3, 1263-1277.

[10] R.-J. van Putten, J. C. van der Waal, E. de Jong, C. B. Rasrendra, H. J. Heeres, J. G. de Vries, Chem. Rev. 2013 , 113, 1499-1597.

[11] L. Hu, L. Lin, Z. Wu, S. Zhou, S. Liu, Renew. Sustain. Energy Rev. 2017, 74, 230-257.

[12] K. Gupta, R. K. Rai, S. K. Singh, ChemCatChem 2018 , 10, 2326-2349.

[13] X. Kong, Y. Zhu, Z. Fang, J. A. Kozinski, I. S. Butler, L. Xu, H. Song, X. Wei, Green Chem. 2018, 20, 3657-3682.

[14] F. H. Isikgor, C. R. Becer, Polym. Chem. 2015, 6, 4497-4559.

[15] T. Gensch, M. N. Hopkinson, F. Glorius, J. WencelDelord, Chem. Soc. Rev. 2016, 45, 2900-2936.

[16] F. Roudesly, J. Oble, G. Poli, J. Mol. Catal. Chem. 2017, 426, 275-296.

[17] C. Sambiagio, D. Schönbauer, R. Blieck, T. Dao-Huy, G. Pototschnig, P. Schaaf, T. Wiesinger, M. F. Zia, J. Wencel-Delord, T. Besset, et al., Chem. Soc. Rev. 2018, 47, 6603-6743.

[18] J. J. Dong, J. Roger, F. Požgan, H. Doucet, Green Chem. 2009, 11, 1832-1846.

[19] D. Zhao, W. Wang, F. Yang, J. Lan, L. Yang, G. Gao, J. You, Angew. Chem. 2009, 121, 3346-3350.

[20] N. A. B. Juwaini, J. K. P. Ng, J. Seayad, ACS Catal. 2012, 2, 1787-1791.

[21] Y. Cheng, G. Li, Y. Liu, Y. Shi, G. Gao, D. Wu, J. Lan, J. You, J. Am. Chem. Soc. 2016, 138, 4730-4738.

[22] Y. Shang, X. Jie, J. Zhou, P. Hu, S. Huang, W. Su, Angew. Chem. Int. Ed. 2013, 52, 1299-1303.

[23] X. Jie, Y. Shang, P. Hu, W. Su, Angew. Chem. Int. Ed. 2013, 52, 3630-3633.

[24] Y. Kuninobu, K. Kikuchi, Y. Tokunaga, Y. Nishina, K. Takai, Tetrahedron 2008, 64, 5974-5981.

[25] L. Cuesta, T. Soler, E. P. Urriolabeitia, Chem. - Eur. J. 2012, 18, 15178-15189.

[26] H. Wang, G. Wang, P. Li, Org. Chem. Front. 2017, 4, 1943-1946.

[27] C. Pezzetta, L. F. Veiros, J. Oble, G. Poli, Chem. - Eur. J. 2017, 23, 8385-8389.

[28] F. Siopa, V.-A. R. Cladera, C. A. M. Afonso, J. Oble, G. Poli, Eur. J. Org. Chem. 2018, 2018, 6101-6106.

[29] J. M. J. M. Ravasco, C. M. Monteiro, F. Siopa, A. F. Trindade, J. Oble, G. Poli, S. P. Simeonov, C. A. M. Afonso, ChemSusChem 2019, 12, 4629-4635.

[30] S. Murai, F. Kakiuchi, S. Sekine, Y. Tanaka, A. Kamatani, M. Sonoda, N. Chatani, Nature 1993, 366, 529531. 
[31] F. Kakiuchi, S. Murai, Acc. Chem. Res. 2002, 35, 826834.

[32] X.-F. Wu, H. Neumann, ChemCatChem 2012, 4, 447458.

[33] F. Liew, M. E. Martin, R. C. Tappel, B. D. Heijstra, C. Mihalcea, M. Köpke, Front. Microbiol. 2016, 7, DOI 10.3389/fmicb.2016.00694.

[34] T. Fukuyama, N. Chatani, F. Kakiuchi, S. Murai, J. Org. Chem. 1997, 62, 5647-5650.

[35] A. Haito, M. Yamaguchi, N. Chatani, Asian J. Org. Chem. 2018, 7, 1315-1318.

[36] H. Gilman, N. O. Calloway, R. R. Burtner, J. Am. Chem. Soc. 1935, 57, 906-907.

[37] M. del', K. Pina, V. A. Budylin, M. Rodriges, P. B. Terent'ev, Yu. G. Bundel', Chem. Heterocycl. Compd. 1989, 25, 142-146.

[38] T.-Y. Yuen, S. E. Eaton, T. M. Woods, D. P. Furkert, K. W. Choi, M. A. Brimble, Eur. J. Org. Chem. 2014, 2014, 1431-1437.

[39] J. Roger, H. Doucet, Adv. Synth. Catal. 2009, 351, 1977-1990.

[40] D. Ghosh, H. M. Lee, Org. Lett. 2012, 14, 5534-5537.

[41] B.-T. Luo, H. Liu, Z.-J. Lin, J. Jiang, D.-S. Shen, R.Z. Liu, Z. Ke, F.-S. Liu, Organometallics 2015, 34, 48814894.

[42] N. Kaloğlu, M. Kaloğlu, M. N. Tahir, C. Arıcı, C. Bruneau, H. Doucet, P. H. Dixneuf, B. Çetinkaya, İ. Özdemir, J. Organomet. Chem. 2018, 867, 404-412.

[43] B. Li, K. Seth, B. Niu, L. Pan, H. Yang, H. Ge, Angew. Chem. Int. Ed. 2018, 57, 3401-3405.

[44] R. Sala, F. Roudesly, L. F. Veiros, G. Broggini, J. Oble, G. Poli, 2019, DOI 10.26434, ChemRxiv 11342096.v1.

[45] Codification of the compounds complies with the following logic: in compounds, the letters $\mathbf{F}, \mathbf{P}, \mathbf{I}$ and $\mathbf{T}$ refer to the furfural, pyrrole, indole and thiophene core, respectively. In compounds $\mathbf{4 - 1 8} \mathbf{x y}, \mathbf{x}$ refers to the imine starting material and $\mathbf{y}$ refers to the olefin introduced.

[46] Parr, R. G.; Yang, W. Density Functional Theory of Atoms and Molecules; Oxford University Press: New York, 1989. DFT calculations at the M06/[3-21G(f), 6311++G(d,p)]//PBE0/[SDD(f), 6-31G(d,p)] level were performed using the GAUSSIAN 09 package. Solvent effects (toluene) were considered by means of the PCM model. A complete account of the computational details and the corresponding list of references are provided as SI.

[47] U. Helmstedt, E. Clot, Chem. - Eur. J. 2012, 18, 11449-11458.

[48] For a previous density functional study of the Murai reaction, see: a) T. Matsubara, N. Koga, D. G. Musaev, K. Morokuma, J. Am. Chem. Soc. 1998, 120, 12692-12693; b) T. Matsubara, N. Koga, D. G. Musaev, K. Morokuma, Organometallics 2000, 19, 2318-2329.
[49] L. Álvarez-Rodríguez, J. A. Cabeza, P. GarcíaÁlvarez, E. Pérez-Carreño, D. Polo, Inorg. Chem. 2015, 54, 2983-2994.

[50] $\mathbf{J}$ and $\mathbf{J}$ ' correspond to the same alkyl complex, with different conformation of the alkyl ligand. 
